This a pre-publication, uncorrected proof and is provided for information only. The citation for the published journal paper is: Duffy, A., Dawson, D. L., \& Das Nair, R. (2016). Pornography addiction in adults: a systematic review of definitions and reported impact. The Journal of Sexual Medicine, 13(5), 760-777.

\title{
Self-perceived pornography addiction in adults: A systematic review of definitions and reported impact
}

\begin{abstract}
Self-perceived 'pornography addiction' (SPPA) has increasingly emerged as a concept within research and popular culture, and commentators warn of the reported negative impact that it has. Despite this, 'pornography/porn addiction' is not a formally recognized disorder and there is disagreement amongst researchers regarding its definition, or whether it exists at all. Therefore, how SPPA is operationalized often varies, and this is likely to influence the conclusions made about the impact of SPPA. This review provides an overview of the definitions of SPPA in research investigating the impact of SPPA. We found that SPPA is most frequently operationalized as excessive pornography-use and negative consequences. As a result, researchers tended to focus on the frequency of pornography use and related impact as determinants of SPPA. SPPA is reported to impact the user and their partners in similar ways, such as increased feelings of isolation and relationship breakdowns. However, we found a number of methodological limitations of the primary studies, which limit the strength of the conclusions that can be drawn. Limitations include the lack of representative samples, and inadequate measures of selfperceived pornography addiction and its impact. In light of these findings, the review concludes with recommendations for future research.
\end{abstract}

Keywords: Pornography; addiction; review; definitions; impact 


\section{Introduction}

There has been a steady increase in the study of addiction to pornography since the 1970s, with an explosion of publications following the advent of the internet and easily accessible pornography since the mid-1990s ${ }^{1}$. With the increase of access to pornography, there has also been an increase in the number of people seeking treatment for their perceived problematic pornography use ${ }^{2,3}$. Consequently, the concept of 'pornography addiction' has emerged within clinics and professional discourse ${ }^{4,5}$, has gained traction within popular culture, and is prevalent in existing online discourse.

However, there remains controversy over whether 'pornography addiction' as a clinical disorder exists, and certainly no agreed diagnostic criteria or recommended guidelines for 'treatment' have been developed. Indeed, whilst 'pornography addiction' has not been accepted and classified as a psychological disorder in diagnostic manuals, researchers have proposed 'Hypersexual Disorder', which included excessive pornography use as a symptom ${ }^{6}$, for Section III of the DSM-5 which lists conditions requiring further study ${ }^{7}$. However, the DSM-5 rejected the proposal of Hypersexual Disorder. Nevertheless, a growing body of research suggests that SPPA is a real phenomenon and can be devastating to the 'sufferer' (and their intimate partners).

In contrast, however, opponents of the construct of SPPA suggest it is a morallyconstructed concept designed to maintain sexual order ${ }^{8}$. Some critics suggest the function of an addiction narrative is not to provide a consensual understanding of the phenomenon, but to support the argument that society needs to be protected to stay safe and healthy ${ }^{8}$, and to construct a platform from where 'experts' can impose sanctions for 'our own good'. When applied to pornography viewing, an addiction narrative may serve to impose the parameters of what is considered 'normal' and 'safe' within the current moral and social context, and to discipline or treat those who transgress these. 
Due to the lack of consensus regarding an operational definition of SPPA, or indeed 'pornography' more broadly ${ }^{9}$, a plethora of terms are used in this area to refer to what is considered problematic pornography usage: compulsive viewing ${ }^{9,10}$, impulsive viewing ${ }^{11}$, excessive viewing ${ }^{12}$, and hypersexual disorder ${ }^{6,13,14}$. However, terms that are used interchangeably render 'pornography addiction' "a malleable concept develop(ed) out of a melting pot of different emerging fields of knowledge" ${ }^{1}$ (p.244). In addition, definitions differ in terms of whether the focus is on objective behavior or subjective experience ${ }^{15}$, and as a result, research pertaining to the impact of pornography addiction can be inconsistent.

For researchers to ensure they are measuring psychological phenomena and prevent subjectivity, specifications of measurable and observable conditions must be outlined. Yet how do we operationally define 'pornography addiction' if there is no agreed definition of pornography, and addiction is enshrouded in controversy? Furthermore, research that measures the impact of pornography addiction may be using undefined concepts. Consequently, there may be other variables that relate to the impact pornography addiction has on an individual, rather than pornography use per se.

Given that research influences clinical practice, policy makers and social understanding, researchers have a responsibility to minimize bias and maximize the accuracy of information that is communicated to the research community and public.

\section{Aims}

This review aimed to examine what the supposed impact of SPPA is, and how the concept is operationalized.

For the purpose of this review, the terms pornography addiction and selfperceived pornography addiction will be used. This maintains consistency and draws 
upon a term popular in our culture. However, this is not to suggest that we (the authors) subscribe to the notion that this behavior is situated within a disease or diagnostic model.

\section{Methods}

\section{Literature Searches}

The following databases were searched for both quantitative and qualitative papers up to November 2015: CINAHL (2001-2015), Embase (1974-2015), Medline (1946-2015), PsychARTICLES (1980), and PsychInfo (1806-2015). Terms used were: porn*, sexually explicit material, SEM, erotic*, non-paraphilic, cyberpornography, addict*, problematic, excess ${ }^{*}$, compul $^{*}$, impul*, impact, effec* ${ }^{*}$, behav*, and cause. Terms were combined as appropriate. An asterisk after a term means that all terms that begin with that root were included in the search.

\section{Eligibility Criteria}

Quantitative and qualitative studies were included if they were available in English and published in peer-reviewed journals. Although not without the potential for political bias, peer-reviewed journals are viewed as adhering to the highest quality standard of publication ${ }^{16}$. Furthermore, peer-reviewed journals arguably have the greatest impact on research, treatment, and policy, and therefore focusing on these papers was considered important for the review given that their conclusions are likely to have the largest influence. Therefore, the following literature were excluded: books and book chapters, conference papers, policy papers, theses, and secondary literature (meta-analyses). Given that the topic is relatively contemporary, it was unlikely that a wealth of papers would be available; therefore, to minimize further restrictions, the search encompassed papers regardless of methodology.

Studies were required to reference (1) an addiction to pornography (or a variant of the term addiction), and (2) the impact of pornography addiction (or variants of). For 
the purpose of this review, articles that did not include data on the impact of pornography addiction were excluded, as the relationship between the impact of pornography addiction and how it was defined was of specific interest. Articles that specifically examined the impact of pornography addiction as a disorder in its own right were included, whereas papers that detailed pornography use as a secondary behavior were not. Due to the potential limited number of studies, papers that used terms that could encompass additional behaviors, such as cybersex addiction, but where pornography use was the primary behavior described, were included. As our interest was in pornography that was considered legal in much of Western Europe and North America, papers detailing adolescent or child populations, or other illegal activities, were excluded.

Details of the search process are provided in Figure 1. A total of 9332 studies were initially identified when searching for topic only. After reviewing the titles and abstracts, 86 papers remained. Literature that were not peer reviewed journal articles were removed, leaving 51 articles. Reference lists of these articles were reviewed, identifying eight additional papers for full text review. Following a more detailed review and application of the inclusion and exclusion criteria, specifically whether articles focused on the impact of self-perceived pornography addiction, ten eligible papers were left for the review.

\section{Data Extraction}

The definitions and impact of SPPA, and general characteristics of the studies, were extracted from each study by the primary author, with audit checking on $50 \%$ of the papers by the other authors, and are presented in Table I. Any disagreements were reviewed and discussed until consensus was reached. The studies were differentiated according to the research method employed (quantitative/qualitative) in order to assess their methodological quality appropriately, and are presented in Tables II and III, respectively. 


\section{Assessment of Methodological Quality of Studies}

The methodological approach to mixed-method syntheses as proposed by the Joanna Briggs Institute (JBI; http://www.joannabriggs.org) was used, whereby data extraction and syntheses occurred separately before being combined in a final synthesis. Methodological quality for quantitative research was assessed using criteria adapted from the JBI Meta-Analysis of Statistics Assessment and Review Instrument (JBI-MAStARI; http://www.joannabriggs.org), shown in Table II. Methodological quality for qualitative research was assessed using recommended criteria for qualitative research, shown in Table III ${ }^{17}$.

\section{Results}

\section{Quantitative Studies}

Five studies used a quantitative methodology; four examined the impact of pornography addiction on the user ${ }^{18-21}$ and one examined the impact of SPPA on the partner of the user $^{12}$.

In terms of sampling, two studies specifically recruited individuals who subjectively perceived their pornography use to be problematic ${ }^{18,20}$, and four recruited from a student population and included individuals who did not meet this criteria. Two studies used male-only samples ${ }^{19,21}$ and two studies included males and females ${ }^{18,20}$. Pyle and Bridges ${ }^{12}$ used only female partners of male individuals they perceived were addicted to pornography. Four ${ }^{18-21}$ used a self-selecting sample, whereas Pyle and Bridges ${ }^{12}$ did not detail how they recruited participants. Only one study used a control group ${ }^{19}$. All used samples from the USA, and non-heterosexuals were excluded. All four studies reported participant demographics clearly with sample sizes ranging from 37 to 1215. 
Of the five studies, one did not provide a clear definition of pornography addiction ${ }^{20}$ and two stated that they did not provide participants with a definition of pornography 12,19

Quantitative measures were used in two ways: (1) to measure SPPA, and (2) to measure the impact of SPPA (Table I). All studies detailed the measures used, however all but one study ${ }^{18}$ included single-item measures, adapted, non-validated measures, and measures which assessed variables that were not specific to pornography use and/or addiction. Only Prause et al. ${ }^{20}$ used a measure specific to pornography use (Pornography Consumption Effects Scale, PCES ${ }^{22}$ ) to measure impact, although the PCES scores were not discussed in their results or discussion sections.

Single-item measures of frequency were used to assess SPPA in three of the studies ${ }^{12,19,21}$, although Levin et al. ${ }^{19}$ and Twohig et al. ${ }^{21}$ also employed a measure of experiential avoidance (The Acceptance and Action Questionnaire-II; AAQ-II ${ }^{23}$ ) and a cut off score on an outcomes scale (Cognitive and Behavioral Outcomes of Sexual Behavior Questionnaire; CBSOB ${ }^{24}$ ) respectively. In contrast, Prause et al. ${ }^{20}$ used a combination of avoidance, and sex-related measures (Behavioral Inhibition Scale/Behavioral Activation Scale; BIS/BAS ${ }^{25}$; Sexual Excitation Scale/Sexual Inhibition Scale; SIS/SES ${ }^{26}$; Sexual Compulsivity Scale; SCS ${ }^{27}$; Sexual Desire Inventory; SDI ${ }^{28}$ ) and Grubbs et al. ${ }^{18}$ employed the Cyber Pornography Use Inventory; CPUI-9 ${ }^{29}$.

Twohig et al. ${ }^{21}$ assessed the impact of SPPA using measures designed to assess level of impairment due to sexual behaviors (SCS) and Levin et al. ${ }^{19}$ used measures which assessed level of impairment in social functioning (Social Functioning Questionnaire; $\mathrm{SFQ}^{30}$ ) and mood ratings (Depression Anxiety \& Stress Scale-21; DASS$21^{31}$ ). Grubbs and colleagues ${ }^{18}$ measured the impact of SPPA on psychological distress 
using the Centre for Epidemiologic Studies Depression Scale-10 (CES-D ${ }^{32}$ ), the Generalized Anxiety Disorder-7 ${ }^{33}$, the Perceived Stress Scale ${ }^{34}$, the State Anger Subscale of the State-Trait Anger Scale ${ }^{35}$, as well as measures of personality (the Neuroticism subscale of the Big Five Inventory ${ }^{36}$ ). Prause et al. ${ }^{20}$ measured cognitive and behavioral outcomes, such as worry and actual negative outcomes (Cognitive and Behavioral Outcomes of Sexual Behavior Scale; CBOSB), positive and negative effects of pornography consumption (PCES ${ }^{22}$ ) and emotion ratings, drawn from both the Positive and Negative Affect Rating Scale ${ }^{37}$ and combined with items from Heiman and Rowland ${ }^{38}$ to measure both general and sexuality specific affect. Pyle and Bridges ${ }^{12}$, Levin et al. ${ }^{19}$, and Prause et al. ${ }^{20}$ used single-item measures to ask participants' subjective view of the effects of their or their partner's pornography use.

All studies employed a cross-sectional design, thus limiting the causalityimplying assumptions that can be made from the findings; only one paper highlighted this as a limitation of their study ${ }^{19}$. One study ${ }^{18}$ extended their methods to include 2 -wave longitudinal data from a one year follow-up using a subset of their sample $(n=106)$.

\section{Qualitative Studies}

Five studies employed qualitative methodologies ${ }^{39-43}$. One ${ }^{39}$ explored the impact of SPPA on the user and the remaining four ${ }^{40-43}$ explored the impact of SPPA on the partner of the user. Sample sizes ranged from 14 to 302. Only female partners of perceived pornography addicts were recruited in four of the studies ${ }^{40-43}$, whilst Cavaglion 39 recruited only male participants who perceived their pornography use as problematic. All studies excluded participants who were not heterosexual. Two studies used Italian samples ${ }^{39,40}$; three used North American samples ${ }^{41-43}$. 
Only one study met the full criteria for rich rigor ${ }^{42}$. The other studies met moderate criteria for rich rigor; however all lacked a justification as to the homogeneity of the samples. In terms of credibility, all studies provided detail regarding their analytic method with two providing extensive information ${ }^{39,42}$. Studies were mostly transparent about the challenges they faced and self-reflexive regarding their potential biases, meeting the criteria for sincerity. All provided some level of resonance and provided new insights, and in turn extended knowledge meeting the criteria for significant contribution. Furthermore, four studies interlinked their method and findings with their stated goals, meeting the full criteria for meaningful coherence. Most of the papers provided moderately sufficient detail to assess the study's ethical clarity.

Of the five studies, Zitzman and Butler ${ }^{42}$ and Bergner and Bridges ${ }^{43}$ provided the most clear definition of SPPA using diagnostic characteristics of addiction, however these were subjective accounts. King ${ }^{41}$ did not provide a definition at all.

\section{Definitions}

Researchers commonly 'borrowed' from the broader psychiatric literature relating to sexual addiction to operationalize SPPA. Definitions therefore made reference to tolerance and withdrawal symptoms; appetitive behaviors, avoidance of intrusive thoughts, urges, and desires as a motivator for viewing pornography, emotional regulation, 'excessive' time spent viewing, dependency, negative outcomes of viewing, relapse cycles, and failed attempts to quit pornography use.

The majority of studies provided a definition of SPPA and eight described the framework they positioned their definitions within ${ }^{12,18-21,39-43}$. To this end, terms such as addiction, compulsive sexual behaviors, problematic pornography viewing and pornography-dependence were often used interchangeably in the body of text across all, except two studies ${ }^{19,20}$, with most making reference to the debate regarding terms used 
to describe problematic pornography viewing ${ }^{18,21,39,40,42,43}$. Indeed Zitzman and Butler ${ }^{42}$, went so far as to reject any debate stating that "Resistance to using the term addiction is perhaps more a reflection of cultural sexual liberality and permissiveness than any lack of symptomatic and diagnostic correspondence with other forms of addiction" (p. 212). Different terms can imply different pathogenic mechanisms and as such infer different treatment targets, and may also elucidate the explanatory framework utilized by the authors. Nevertheless, four studies described the behavior as "addictive" and situated their understanding within a medical conceptualization, making comparisons to substance addiction 12,19,40,42; whereas three studies which did not utilize "addiction" in their analysis, instead drew on a behavioral conceptualization related more to "maladaptive behavior" governed by impulses and intrusions ${ }^{20,21,39}$. Bergner and Bridges ${ }^{43}$ drew on language commonly situated within the sex addiction discourse, however, offered that SPPA is an individual's attempt to repair themselves "following an insult to the masculine self-image ${ }^{44}$, to recover from explicitly sexual childhood degradations ${ }^{45}$, or to triumph over very damaging childhood sexual indoctrinations ${ }^{46,47 \% ”}$ (p201).

Although the definitions of SPPA were mostly provided in articles, with the exception of Prause et al. ${ }^{20}$, it was unclear whether participants were provided with a definition in five of the studies $18,19,21,41,43$. Half of the studies relied on the participants' own definition of SPPA $12,39,40,42,43$. Given the subjectivity of definitions, findings may prove difficult to generalize as different studies may have formulated and measured different concepts.

Recurrent themes revealed SPPA, or variants of, to be defined in part by the amount of pornography consumed ${ }^{12,19,40,43}$; an 'excessive' amount was posited as a measurable indicator. Themes regarding agency were also apparent in the definitions of SPPA with difficulty regulating emotions and controlling consumption of pornography 
being described as both characteristics and symptoms ${ }^{20,21}$. Finally, the presence of negative consequences, to both the individual and "human community" ${ }^{39}$ (p.309) was commonly used to define SPPA ${ }^{12,19,43}$.

\section{Correlates and Possible Outcomes of Self-Perceived Pornography Addiction}

Four studies investigated and found a negative impact on the partners of the selfperceived pornography addict ${ }^{40-43}$, five studies investigated and found a negative impact on the self-perceived pornography addict ${ }^{12,18,19,21,39}$, and Prause et al.'s ${ }^{20}$ examination of emotional dysregulation found a positive impact on the pornography user. This study found that those who reported problems with regulating their pornography consumption experienced less emotional dysregulation than those who denied problems regulating their pornography consumption (control group), in response to sexual films. In addition, they found that the control group expressed more anger in response to sexual films.

Levin et al. ${ }^{19}$ assessed the relationship between frequent viewing, experiential avoidance and a number of psychosocial outcome variables (anxiety, stress, depression, social functioning, and viewing problems). They found that frequent viewing significantly predicted all outcome variables (although with modest effect sizes), with increased viewing leading to greater problems. In addition, they found that experiential avoidance moderated the relationship between frequencies of viewing and predicted viewing problems and anxiety in individuals with clinical levels of avoidance but not in individuals with non-clinical levels. Grubbs et al. ${ }^{18}$ reported a similar relationship between frequency of viewing and psychological distress, however, this was found to be fully mediated by perceived addiction. These findings suggest that psychological distress may not occur as a result of the pornography use itself but may be due to the attitudes individuals hold about their pornography use. 
Twohig et al. ${ }^{21}$ found that any viewing of pornography was associated with problems in legal/occupational, psychological/spiritual, social, physical (pain/injury and disease/pregnancy), and behavioral outcomes. They found that between $20 \%$ and $60 \%$ of participants who watched pornography found it to be problematic. However, the amount of viewing was not significantly associated with these variables; negative outcomes did not increase as viewing increased. Using mediation analysis, the researchers found that the relationship between viewing pornography and problematic behavioral outcomes was mediated by scores on the SCS, which measures an individual's attempts to control desires.

Pyles and Bridges ${ }^{12}$ found that marijuana and pornography use were both similarly perceived, by the participants, to lower relationship satisfaction; SPPA was perceived to be as damaging as drug addiction. They also demonstrated that when a partner used pornography/marijuana, greater frequency of use, higher secrecy regarding the behavior, relationship commitment, and using in the presence of a significant other were all significantly associated with lower relationship satisfaction. The secrecy of use affected the relationship satisfaction more for partners of pornography users compared to marijuana users. The same variables were associated with perceptions of addictiveness except more so for pornography use than marijuana use.

Recurrent themes related to the negative effects of SPPA were revealed across the studies. Intrapersonal effects on the user and partners included worry ${ }^{21}$, loss of confidence and concentration ${ }^{39}$, increase in shame and feelings of inadequacy ${ }^{42}$, reduction in self-esteem and identity ${ }^{39,40}$, and reduced 'physical well-being' ${ }^{40}$. Interpersonal effects included the breakdown of relationships, deterioration of trust and safety in the relationship ${ }^{12,40,42,43}$, sexual problems ${ }^{39,40,43}$, perceived rejection ${ }^{40,43}$, and a detrimental change in how participants viewed their SPPA partners ${ }^{43}$. Extrapersonal 
impact occurred in relation to increased debt ${ }^{41}$ and detrimental effects in the work-place, such as lost time and resources ${ }^{19,39}$.

Overall, female partners experienced more negative effects than male users, with negative effects being described as "traumatic" and "devastating". As a result of the SPPA, how these participants viewed their partners had fundamentally changed, from being once "good" to inherently "bad" 39,40,42,43.

Largely, however, caution must be taken when interpreting these results given the small coefficients of determinants $\left(0.3-.27^{19}\right)$, varying and poor definitions of SPPA, incomplete ethical clarity and self-reflexivity, lack of objective and relevant measures, and inadequate representative samples.

\section{Discussion}

This review examined the operational definitions and impact of SPPA. Overall, the literature drew upon the existing addiction narrative, whereby similarities with substanceuse disorders were highlighted, or a compulsive narrative which argues sexuallycompulsive behaviors relieve anxiety and help to repair one's self-esteem, all of which are commonly used to describe broader problematic sexual behaviors ${ }^{48}$.

Impact of SPPA focused on either the individual with the perceived pornography addiction or their partner. Negative psychological, physical, and social effects of SPPA were cited as occurring within intrapersonal, interpersonal and extra-personal domains. Research employed different methods and measures, although two studies ${ }^{20,21}$ used the same two measures (SCS and CBOSB) but for different purposes. The methodological quality varied across the reviewed research. The more adequate studies conveyed mixed results regarding the impact of SPPA, offered a more balanced perspective in employing self-defined problematic pornography users, and utilized a theoretical framework for their 
research. These factors should be taken into consideration when drawing conclusions made about the impact of SPPA.

\section{Definitions}

Difficulties with operationalizing SPPA were apparent within the reviewed literature. Authors tended to draw on the broader medicalized addiction framework, relating to selfperceived sex addiction (SPSA), to conceptualize SPPA, with particular attention paid to 'excessive' use and negative consequence variables. As a result, researchers tended to focus on the frequency of pornography use and related impact as determinants of pornography addiction.

However, researchers often used an arbitrary measure of 'excessive pornography use' as equivalent to SPPA, at times without any theoretical justification. For example, Twohig et al. ${ }^{21}$ determined 'high viewing' as viewing pornography more than 10 times in three months and used this metric as an indicator of SPPA. Conversely, Pyle and Bridges ${ }^{12}$ stated daily use was representative of high pornography viewing, the equivalent of viewing pornography around 90 times in a three-month period. Both studies included the frequency of pornography viewing in their definitions of SPPA, yet differed vastly in their definition of 'frequent'. This reflects broader difficulties in operationalizing SPPA and raises the question as to how the concept can be adequately studied when researchers have different understandings of the variables which they claim characterize it. Therefore, findings provided in research that includes frequency of use in the definition of SPPA should be interpreted with caution.

Furthermore, frequency of viewing alone may not be a sufficient indicator of SPPA. Twohig et al. ${ }^{21}$ and Levin et al. ${ }^{19}$ found that attempts to control thoughts and avoidance of pornography, respectively, influenced the impact of pornography viewing. Both identified additional variables which may have contributed to the occurrence of 
SPPA but only one ${ }^{21}$ included them in their definition. Furthermore, Grubbs et al. ${ }^{18}$ concluded that the perception of pornography use is likely to contribute towards the development of SPPA, rather than high amounts of viewing. Conversely, Pyle and Bridges ${ }^{12}$ found that higher frequency of viewing did lead to greater problematic outcomes for the partner; perceived relationship satisfaction decreased with increased viewing. Therefore, it cannot be concluded from the current literature whether frequency of viewing alone can account for negative impact. Perhaps the differences in how variables are operationalized account for these mixed results. Therefore, caution must be taken when findings are collated and used to direct treatment and policy. Furthermore, the relationship between variables operationalized in the definition of SPPA and negative impact may not be a linear one and conceivably, other non-measured factors that contribute to the identified interactions and moderations should be investigated.

Other definitional themes identified included that of agency; whether the selfperceived pornography addict had control of their behavior and was responsible for their actions. Within the disease model, control and responsibility are impaired following the introduction of an external chemical (i.e., drugs and alcohol). When applied to SPPA, the external chemical is replaced with an internal pathological reaction to the 'toxin' of pornography ${ }^{49}$. Critics argue that anti-pornists are invested in this affiliation in order to propagate the belief that SPPA is comparable to substance addiction so as to warrant the sanctions they impose ${ }^{8}$.

In an attempt to create an addiction conceptualization that does not persecute the individual user, researchers convey the individual as not to blame but vulnerable; the behavior (i.e. pornography use) is the 'bad guy'. Pornography allows the user to satiate his (or her) "need to negate his partner's identity...which makes (him) feel power, strength and satisfaction... (and is) achieved by controlling, humiliating, and decreasing the worth 
of women in general" 40 . The 'dangers of pornography' are extended beyond the user, where the man is seen to commit the behavior to the woman's detriment.

However, pornography use has long been entrenched in morality ${ }^{50}$, and SPPA is no exception. When a disease conceptualization is enveloped in morality, stark contrasts become apparent. For example, Zitzman and Butler ${ }^{42}$ initially refer to "compulsive pornography viewing (as) an impulse-control disorder scalable to addictive proportions" (p. 212) and situate the behavior within a neurophysiological framework. However, they provide a definition of pornography which suggests that pornography use is an act of infidelity, threatens relationship security, and convey this as "pornography use combined with concomitant deception" (p. 210) - omitting the terms 'compulsive' and 'addictive' in their results and discussion, instead referring to the behavior as "single minded" and "self-indulgent". Such a premise is likely to lead to a biased conclusion; its value-laden narrative insinuates that "healthy sex cannot be about casual recreation or selfgratification" 8 (p.138), and negates the physiological addictive components, implicit within a medical framework.

Moreover, using negative outcomes to define SPPA can lead to biases. Levin et al. ${ }^{19}$ suggested that a partner using pornography, when the spouse was available for sexual relations, was more indicative of an addiction than if the spouse were out-of-town. This assumes 'healthy' individuals should only seek sexual satisfaction with partners and that to do otherwise is not 'normal'. The qualitative literature has several instances of similar inferences, such that any sexual act committed outside of marital sex is a direct attack on the relationship; pornography use and a healthy relationship are suggested to be mutually exclusive ${ }^{40-43}$. Interestingly, only one of the studies made reference to the suggestion that people may watch pornography together to augment their sex lives ${ }^{42}$. Given that moralistic persuasions can risk normal behavior being pathologised ${ }^{29}$, it is 
important to take into account the authors' stance on SPPA when considering their research and its implications.

Only Prause et al. ${ }^{20}$ stated participants were provided with a definition of pornography addiction. This is important to maximize validity and ensure that participants are responding to the concept the researchers intended. Participants may have a very different notion of what pornography is and what it means to be addicted, compared to other participants or the researchers, and so the validity of the conclusions may be compromised. For example, in one study ${ }^{12}, 69 \%$ of participants claimed to have never viewed pornography and were not provided with a definition of pornography or pornography addiction. Therefore, their understanding of pornography and pornography addiction may have been very different to participants who had viewed pornography. Alternatively, those participants may have been reluctant to admit to using pornography due to feeling embarrassed or ashamed. If this was the case, held attitudes and perceptions about pornography and its users may have influenced their answers, which the study did not capture.

The current definitions of SPPA are not adequate or sufficient to develop a valid diagnostic category. For example, some researchers have defined self-perceived pornography addicts as individuals who cannot regulate their emotions, but Prause et al. ${ }^{20}$ found that self-perceived pornography addicts displayed better emotional regulation than non-addicts. This finding directly contradicts this element of the definition and suggests that current definitions of SPPA are not grounded in robust evidence. Similarly, findings are mixed regarding the relevance of frequency of pornography use in addiction. Relating specifically to treatment, reasons individuals attend for treatment have not yet been discovered because it is unlikely to be just viewing alone which leads to SPPA. Instead, other variables such as avoidance, attitudes, and values may be involved. Before 
we can provide appropriate treatment (if intervention is warranted) these other variables should be investigated, as some may be more appropriate targets for treatment than only attempting to stop the behavior (watching pornography).

This review highlighted the difficult positions researchers find themselves in: in order to empirically add to the literature base for investigating SPPA, researchers must draw on existing validated measures and theoretical understandings. However, currently, there is a distinct lack of measures specifically relating to self-perceived pornography addiction and so researchers are having to use the next best thing; measures related to broader sexually-related disorders. Difficulties that arise from this mean that assessment tools, such as the SCS, which measure all sexual behaviors, may fail to identify outcomes relating to pornography use specifically, instead results may be unclear and confounded with the addition of broader sexual behaviors.

\section{Correlates and Possible Outcomes of Self-Perceived Pornography Addiction}

The studies reviewed examined the possible impact of SPPA on users or their partners using cross-sectional designs, with one study also employing longitudinal research methods. Of course, retrospective cross-sectional designs cannot be used to draw causal conclusions ${ }^{51}$ about any associations between SPPA and potential outcomes given that they are measured simultaneously; it may be difficult to ascertain whether individuals perceived their pornography use to be problematic before or after they experienced negative outcomes. Moreover, the longitudinal study used a 2-wave design and a much smaller subset $(n=106)$ of their original sample $(n=1215)$ which substantially limits causality-related analyses and so findings are likely to be tentative at best.

Nine of the ten studies reported evidence that SPPA had a detrimental impact on individuals or their partners. However, a number of important methodological issues must be considered. Firstly, SPPA and its impact were often assessed using a single-item 
measure which research suggests are an adequate measure of complex constructs ${ }^{4,52}$. If an individual's experience is multi-dimensional (i.e. physiological, behavioral, and cognitive), it may be challenging for them to convey this using a single item, and assumptions can be made which omit potentially important information. Secondly, a number of studies used under-defined concepts and definitions, for example, Levin et al. ${ }^{19}$ used a single-item measure to assess impaired functioning resulting from SPPA, but did not provide a definition of functioning, and so it is uncertain whether the researchers are measuring the same construct for all participants.

Thirdly, three of the studies ${ }^{18,20,21}$, suggested that an individual's values and morals associated with their pornography use may have contributed to their perceived pornography addiction, and Prause et al. ${ }^{20}$ further suggested that conflict with their held values may have led to their distress. Therefore, SPPA may actually result from a conflict in values rather than pornography use per se.

Research that examined the impact of SPPA on the partners of self-perceived pornography addicts found that they experienced a number of negative effects such as feelings of betrayal, shame, and isolation. These effects were attributed to the behavior of the self-perceived pornography addict. However, research investigating the effects of pornography use has shown that women who attribute their partners' pornography use to an inadequacy about themselves experience a greater level of distress ${ }^{53}$. None of the studies reviewed considered the characteristics of the partners of self-perceived pornography addicts, yet it is possible that negative outcomes are affected by factors such as thinking styles and attitudes (e.g. how we perceive information), which may lead to these feelings of inadequacy.

There were also concerns regarding the measures used to make conclusions about the impact of SPPA. Many relied on adapted and non-validated measures that were not 
necessarily theoretically driven, and were derived from a non-clinical sample, and thus are difficult to generalize findings. For example, Twohig et al. ${ }^{21}$ used a median cut-off (58\%) from a non-clinical sample to determine an arbitrary level of problematic cognitive and behavioral outcomes of SPPA.

Of the six validated measures employed, only two related to SPPA as a distinct behavior (PCES, CPUI-9), with the remaining five related to sexual addiction (SCS; SIS/SES; SDI; CBOSB). Furthermore, half were evaluated using a student sample (CBOSB, CPUI-9, PCES and SIS/SES), only two were evaluated using a representative sample of mixed sexual orientations (heterosexual, homosexual, bisexual and lesbian; PCES and SCS), and only three with more than one gender (male and female) (PCES, SDI and SCS).

Furthermore, all of these measures were self-report instruments which, whilst they did allow for a subjective perspective, are also susceptible to socially-desirable responding, particularly given the topic and as such have been suggested as inappropriate in measuring this population ${ }^{20,48}$. With this in mind, it is important to note that only Grubbs et al. ${ }^{18}$ employed a measure of socially desirable responding (Marlow-Crowne Social Desirability Scale ${ }^{54}$ ), and found that their results remained significant even after controlling for this.

In relation to the design of the studies, only one employed a longitudinal design with follow-up assessments ${ }^{18}$, and only one other noted this as a limitation ${ }^{19}$. Instead, despite the cross-sectional limitations, such as difficulty making causal inferences, the majority of studies assumed a 'severe and on-going' causal effect and suggested that marital, financial, and employment problems exist because of SPPA. None of the authors considered that individuals may turn to pornography because of pre-existing problems. Therefore, it is unclear as to whether the psychological and behavioral factors said to be 
outcomes of SPPA existed prior to the study, or indeed whether people used pornography more when they were unhappy in those areas of their lives.

All of the studies employed heterosexual, Western samples with participants from either America or Italy. Most studies only considered self-perceived pornography addicts to be male, and female participants were considered as partners of male self-perceived pornography addicts. However, findings from two of the reviewed studies indicated that people who perceived their pornography use to be problematic were not a homogenous group ${ }^{20,39}$. Moreover, Cavaglion ${ }^{39}$ found that their sample characteristics differed to those previously cited as 'typical' for this population, as participants did not have previous trauma, high comorbidity, or other addictions. Women are often excluded from samples with researchers citing evidence to suggest they view pornography less frequently than men ${ }^{55}$, however, evidence for this is often based on methodologically poor research. Furthermore, evidence is mixed as to whether frequency is indicative of SPPA $^{1}$ and, as evident in the review, even males who use pornography infrequently may report their viewing as problematic. Therefore, this suggests that the homogenous samples often used in research are inadequate to represent what is increasingly evidenced to be a diverse population.

\section{Limitations}

The terminology used within this area is value-laden, confusing and jargonistic, and without an agreed conceptualization, authors can choose their own descriptions and as such can differ vastly between papers. Therefore, the terminology searched for in this review may have omitted articles significant to understanding how SPPA is defined and the impact it may or may not have on addicts and others. Moreover, the exclusion of papers detailing 'illegal activities' may be a shortcoming. Some authors may identify illegal activities as potential 'outcomes' of SPPA. Therefore, excluding papers that refer 
to these activities may have selectively biased our conclusions about the impact of SPPA. However, we were clear at the outset that we were only interested in pornography considered legal in most of the Western world. Furthermore, the review excluded literature that was not published within a peer-reviewed journal. Whilst justification for this was to ensure a quality threshold, peer-reviewed journals are vulnerable to their own biases ${ }^{56}$. Therefore future reviews may benefit from including literature from other sources.

Finally, the review found a lack of studies that considered the positive impact of SPPA. Nine of the ten studies focused solely on negative outcomes. This may suggest that there are no positive effects, or perhaps suggests a specific research-focus and publication bias. Therefore, limited conclusions can be drawn regarding any positive impact of SPPA.

\section{Conclusions and Recommendations for Future Research}

In summary, there still exists a debate regarding the definition and etiology of SPPA as distinct from SPSA. Indeed, both concepts remain highly controversial. Even for those who are in support of the concept of sexual behavior disorders, there is a lack of consensus regarding their etiology ${ }^{6}$. As such, the research landscape is shaped by differing theoretical perspectives such as the addiction model ${ }^{7}$, behavioral addictions ${ }^{49}$, impulsivity disorders ${ }^{57}$, obsessive-compulsive spectrum disorders ${ }^{58}$, 'out-of-control' excessive sexual behaviors ${ }^{59}$, and sexually motivated disorders ${ }^{60}$. Difficulties which may arise when applying an addiction model to self-perceived problematic pornography use include the risk of pathologising behaviors which are legal and consensual, distracting attention from deeper issues such as thinking styles and feelings of shame, and disguising an individual's choice and responsiveness ${ }^{61}$. Furthermore, without evidence to suggest one theoretical position as superior to another, clinicians may be at risk of recommending 
treatment which is in line with their theoretical perspective (or personal biases) but at odds with the motivations driving an individual to engage in particular sexual behaviors. For example, a fundamental difference between impulsive and compulsive sexual behaviors, is that a compulsion is driven by a need to reduce anxiety, whereas an impulsion is an urge which demands immediate gratification ${ }^{62}$. Therefore different treatment approaches would be needed. Moreover, recommended treatment will likely address the underlying core assumptions but without a unifying framework, clinicians may be unable to access consistent and reliable research pertaining to assessment and treatment ${ }^{63}$. With this in mind, future research may focus on constructing and testing a unified operational definition and underlying theoretical framework.

Operationalized variables currently measured to assess the presence of SPPA are inadequate and simplistic, and as a result can be misleading. The same problems exist in regards to operationalizing and measuring impact. Furthermore, the structured instruments used to measure SPPA and impact are often inappropriate. As a result, complex experiences are reduced to simplistic constructs and vital information regarding the mechanisms of SPPA is likely to be missed. Therefore, future research would benefit from including measures related to SPPA, perhaps illuminating new theoretical premises to the conceptualization of SPPA. It may be that what is being defined as SPPA is different to the individuals' experience of pornography addiction.

To this end, future research may benefit from continuing to develop, evaluate, and utilize purpose-developed measures related to pornography use. New measures, such as the multi-dimensional Pornography Craving Questionnaire, (PCQ ${ }^{4}$ and CPUI-9 ${ }^{29}$ have recently been developed, however, as is often the case, the measure was developed using a male student sample and is therefore limited in its generalizability. Therefore, the 
literature base would benefit from a measure developed using a representative sample or from validating existing measures using more varied samples.

Currently research relies on homogenous samples, and therefore limits the generalizability of findings. A representative sample would include all genders, with different sexual orientations, and from diverse cultural and ethnic backgrounds. In doing so, research would further our understanding of the behavior of pornography use and SPPA and go further to elucidate its controversies.

\section{References}

1. Voros F. The invention of addiction to pornography. Sexologies. 2009;18(4):243-246.

2. Cooper A, Delmonico DL, Burg R. Cybersex users, abusers, and compulsives: New findings and implications. Sexual Addiction \& Compulsivity: The Journal of Treatment and Prevention. 2000;7(1-2):5-29.

3. Ross MW, Månsson S-A, Daneback K. Prevalence, severity, and correlates of problematic sexual Internet use in Swedish men and women. Archives of Sexual Behavior. 2012;41(2):459-466.

4. Kraus S, Rosenberg H. The Pornography Craving Questionnaire: Psychometric Properties. Archives of Sexual Behavior. 2014;43(3):451-462.

5. Mitchell KJ, Wells M. Problematic Internet experiences: Primary or secondary presenting problems in persons seeking mental health care? Social Science \& Medicine. 2007;65(6):1136-1141.

6. Kafka MP. Hypersexual disorder: A proposed diagnosis for DSM-V. Archives of sexual behavior. 2010;39(2):377-400. 
7. APA APA. Diagnostic and statistical manual of mental disorders (5th Ed.). 2013.

8. Clarkson J, Kopaczewski S. Pornography addiction and the medicalization of free speech. Journal of Communication Inquiry. 2013;37:128-148.

9. Cooper A, Delmonico DL, Griffin-Shelley E, Mathy RM. Online sexual activity: An examination of potentially problematic behaviors. Sexual Addiction \& Compulsivity. 2004;11(3):129-143.

10. Young KS. Understanding Cybersex Addiction. The Amplifier. Vol 9. Fall/Winter 2004 ed: American Psychological Association Division on Media Psychology; 2005.

11. Shapira NA, Lessig MC, Goldsmith TD, et al. Problematic internet use: proposed classification and diagnostic criteria. Depression and anxiety. 2003;17(4):207-216.

12. Pyle TM, Bridges AJ. Perceptions of relationship satisfaction and addictive behavior: Comparing pornography and marijuana use. Journal of Behavioral Addictions. 2012;1(4):171-179.

13. Kaplan MS, Krueger RB. Diagnosis, assessment, and treatment of hypersexuality. Journal of sex research. 2010;47(2-3):181-198.

14. Reid RC, Li DS, Gilliland R, Stein JA, Fong T. Reliability, validity, and psychometric development of the Pornography Consumption Inventory in a sample of hypersexual men. Journal of sex \& marital therapy. 2011;37(5):359385.

15. Grubbs JB, Exline JJ, Pargament KI, Hook JN, Carlisle RD. Transgression as addiction: Religiosity and moral disapproval as predictors of perceived addiction to pornography. Archives of sexual behavior. 2015;44(1):125-136. 
16. Harnad S. Free at last: The future of peer-reviewed journals. D-Lib Magazine. $1999 ; 5(12)$.

17. Tracy SJ. Qualitative quality: Eight "big-tent” criteria for excellent qualitative research. Qualitative inquiry. 2010;16(10):837-851.

18. Grubbs JB, Stauner N, Exline JJ, Pargament KI, Lindberg MJ. Perceived Addiction to Internet Pornography and Psychological Distress: Examining Relationships Concurrently and Over Time. 2015.

19. Levin ME, Lillis J, Hayes SC. When is online pornography viewing problematic among college males? Examining the moderating role of experiential avoidance. Sexual Addiction \& Compulsivity. 2012;19(3):168-180.

20. Prause N, Staley C, Fong TW. No evidence of emotion dysregulation in "hypersexuals" reporting their emotions to a sexual film. Sexual Addiction \& Compulsivity. 2013;20(1-2):106-126.

21. Twohig MP, Crosby JM, Cox JM. Viewing Internet pornography: For whom is it problematic, how, and why? Sexual Addiction \& Compulsivity. 2009;16(4):253-266.

22. Hald GM, Malamuth NM. Self-perceived effects of pornography consumption. Archives of Sexual Behavior. 2008;37(4):614-625.

23. Bond FW, Hayes SC, Baer RA, et al. Preliminary psychometric properties of the Acceptance and Action Questionnaire-II: A revised measure of psychological inflexibility and experiential avoidance. Behavior Therapy. 2011;42(4):676-688.

24. McBride KR, Reece M, Sanders SA. Predicting negative outcomes of sexuality using the Compulsive Sexual Behavior Inventory. International Journal of Sexual Health. 2008;19(4):51-62. 
25. Carver CS, White TL. Behavioral inhibition, behavioral activation, and affective responses to impending reward and punishment: The BIS/BAS scales. Journal of Personality and Social Psychology. 1994;67(2):319.

26. Janssen E, Vorst H, Finn P, Bancroft J. The Sexual Inhibition (SIS) and Sexual Excitation (SES) Scales: I. Measuring sexual inhibition and excitation proneness in men. Journal of Sex Research. 2002;39(2):114-126.

27. Kalichman SC, Rompa D. Sexual sensation seeking and sexual compulsivity scales: validity, and predicting HIV risk behavior. Journal of personality assessment. 1995;65(3):586-601.

28. Spector IP, Carey MP, Steinberg L. The Sexual Desire Inventory: Development, factor structure, and evidence of reliability. Journal of Sex \& Marital Therapy. 1996;22(3):175-190.

29. Grubbs JB, Volk F, Exline JJ, Pargament KI. Internet pornography use: Perceived addiction, psychological distress, and the validation of a brief measure. Journal of Sex \& Marital Therapy. 2015;41(1):83-106.

30. Tyrer P. Personality disorder and social functioning. In: Peck DF, Shapiro CM, eds. Measuring human problems: A practical guide. Chichester: John Wiley and Sons; 1990:119-142.

31. Lovibond SH, Lovibond PF. Manual for the Depression Anxiety Stress Scales. 2nd ed. Sydney: Psychology Foundation of Australia; 1995.

32. Cole JC, Rabin AS, Smith TL, Kaufman AS. Development and validation of a Rasch-derived CES-D short form. Psychological assessment. 2004;16(4):360.

33. Spitzer RL, Kroenke K, Williams JB, Löwe B. A brief measure for assessing generalized anxiety disorder: the GAD-7. Archives of internal medicine. 2006;166(10):1092-1097. 
34. Cohen S, Kamarck T, Mermelstein R. A global measure of perceived stress. Journal of health and social behavior. 1983:385-396.

35. Spielberger CD, Jacobs G, Russell S, Crane RS. Assessment of anger: The statetrait anger scale. Advances in personality assessment. 1983;2:159-187.

36. John OP, Donahue EM, Kentle RL. The big five inventory: Versions 4a and 54, institute of personality and social research. University of California, Berkeley, CA. 1991.

37. Watson D, Clark LA, Tellegen A. Development and validation of brief measures of positive and negative affect: the PANAS scales. Journal of personality and social psychology. 1988;54(6):1063.

38. Heiman JR, Rowland DL. Affective and physiological sexual response patterns: The effects of instructions on sexually functional and dysfunctional men. Journal of psychosomatic research. 1983;27(2):105-116.

39. Cavaglion G. Cyber-porn dependence: voices of distress in an Italian internet self-help community. International journal of mental health and addiction. 2009;7(2):295-310.

40. Cavaglion G, Rashty E. Narratives of suffering among Italian female partners of cybersex and cyber-porn dependents. Sexual Addiction \& Compulsivity. 2010;17(4):270-287.

41. King S. The impact of compulsive sexual behaviors on clergy marriages: Perspectives and concerns of the Pastor's wife. Sexual Addiction \& Compulsivity: The Journal of Treatment and Prevention. 2003;10(2-3):193-199.

42. Zitzman ST, Butler MH. Wives' experience of husbands' pornography use and concomitant deception as an attachment threat in the adult pair-bond relationship. Sexual Addiction \& Compulsivity. 2009;16(3):210-240. 
43. Bergner RM, Bridges AJ. The significance of heavy pornography involvement for romantic partners: Research and clinical implications. Journal of Sex \&Marital Therapy. 2002;28(3):193-206.

44. Coleman E. Compulsive sexual behavior: New concepts and treatments. Journal of Psychology \& Human Sexuality. 1991;4(2):37-52.

45. Bergner RM. Money's" lovemap" account of the paraphilias: a critique and reformulation. 1988.

46. Money J. Paraphilias: phenomenology and classification. American Journal of psychotherapy. 1984.

47. Money J. Lovemaps: Clinical concepts of sexual/erotic health and pathology, paraphilia, and gender transposition of childhood, adolescence, and maturity. Ardent Media; 1986.

48. Hook JN, Hook JP, Davis DE, Worthington Jr EL, Penberthy JK. Measuring sexual addiction and compulsivity: A critical review of instruments. Journal of Sex \& Marital Therapy. 2010;36(3):227-260.

49. Carnes P. The sexual addiction. CompCare Publications; 1983.

50. Sherkat DE, Ellison CG. The cognitive structure of a moral crusade: Conservative Protestantism and opposition to pornography. Social Forces. 1997;75(3):957-980.

51. Hennekens CH, Buring JE, Mayrent SL. Epidemiology in Medicine. Little, Brown; 1987.

52. Loo R. A caveat on using single-item versus multiple-item scales. Journal of Managerial Psychology. 2002;17(1):68-75. 
53. Bridges AJ, Bergner, R. M. \& Hesson-McInnis, M. Romantic Partners Use of Pornography: Its Significance for Women. Journal of Sex \& Marital Therapy. 2003;29(1):1-14.

54. Reynolds WM. Development of reliable and valid short forms of the MarloweCrowne Social Desirability Scale. Journal of clinical psychology. 1982;38(1):119-125.

55. Morgan EM. Associations between young adults' use of sexually explicit materials and their sexual preferences, behaviors, and satisfaction. Journal of Sex Research. 2011;48(6):520-530.

56. Callaham M, Wears RL, Weber E. Journal prestige, publication bias, and other characteristics associated with citation of published studies in peer-reviewed journals. Jama. 2002;287(21):2847-2850.

57. Mick TM, Hollander E. Impulsive-compulsive sexual behavior. CNS spectrums. 2006;11(12):944-955.

58. Black D, W. Compulsive Sexual Behavior: A Review. Journal of Psychiatric Practice®. 1998;4(4):219-229.

59. Bancroft J, Vukadinovic Z. Sexual addiction, sexual compulsivity, sexual impulsivity, or what? Toward a theoretical model. Journal of sex research. 2004;41(3):225-234.

60. Kafka M. Paraphilia-related disorders: The evaluation and treatment of nonparaphilic hypersexuality. Principles and practice of sex therapy. 2007;4:442-476.

61. Satel S, Lilienfeld SO. Addiction and the brain-disease fallacy. Frontiers in psychiatry. 2013;4. 
62. Giugliano JR. Sexual addiction: Diagnostic problems. International journal of mental health and addiction. 2009;7(2):283-294.

63. Kafka MP, Hennen J. Hypersexual desire in males: Are males with paraphilias different from males with paraphilia-related disorders? Sexual Abuse: A Journal of Research and Treatment. 2003;15(4):307-321. 
Figures and Tables. 


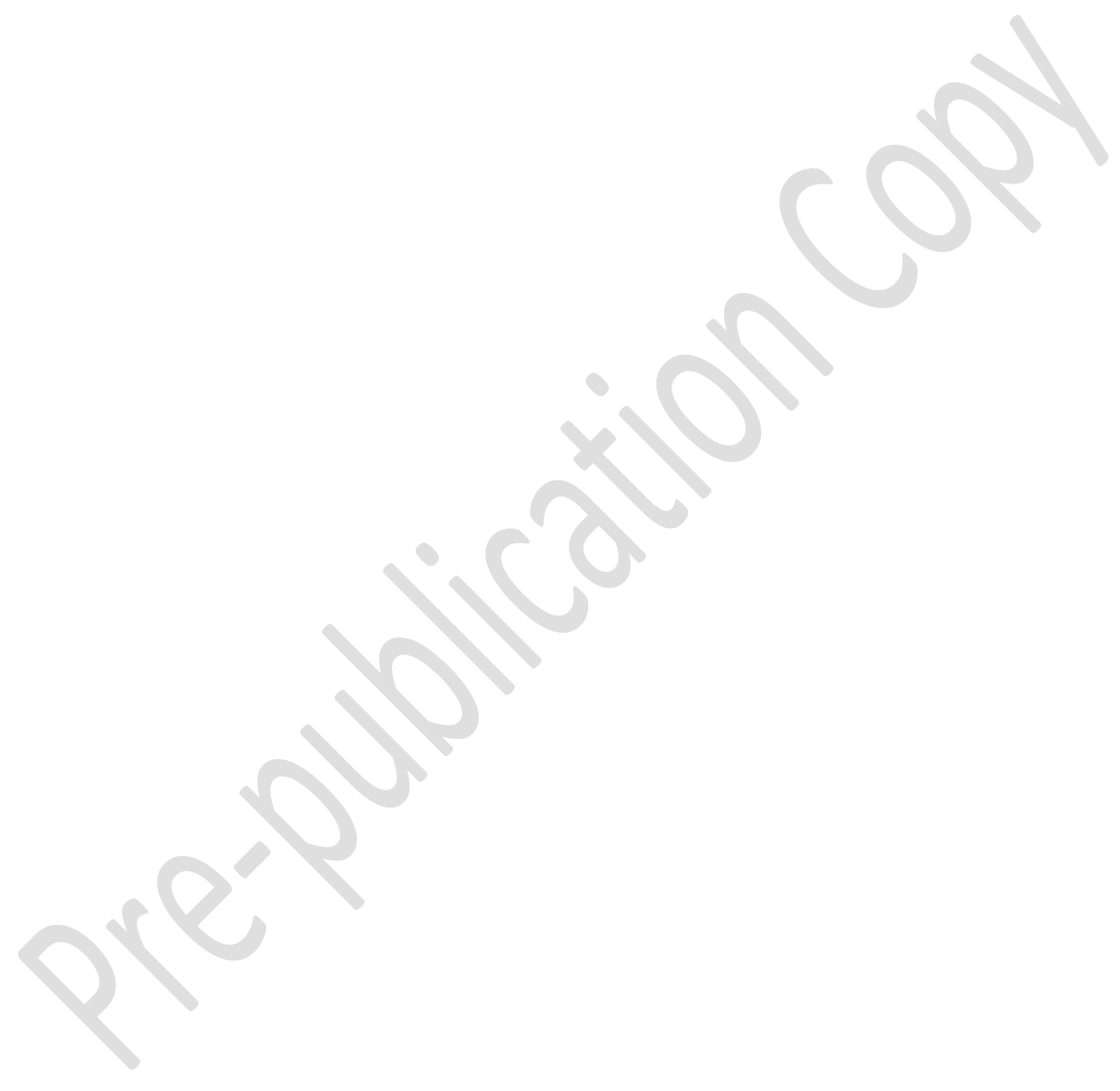




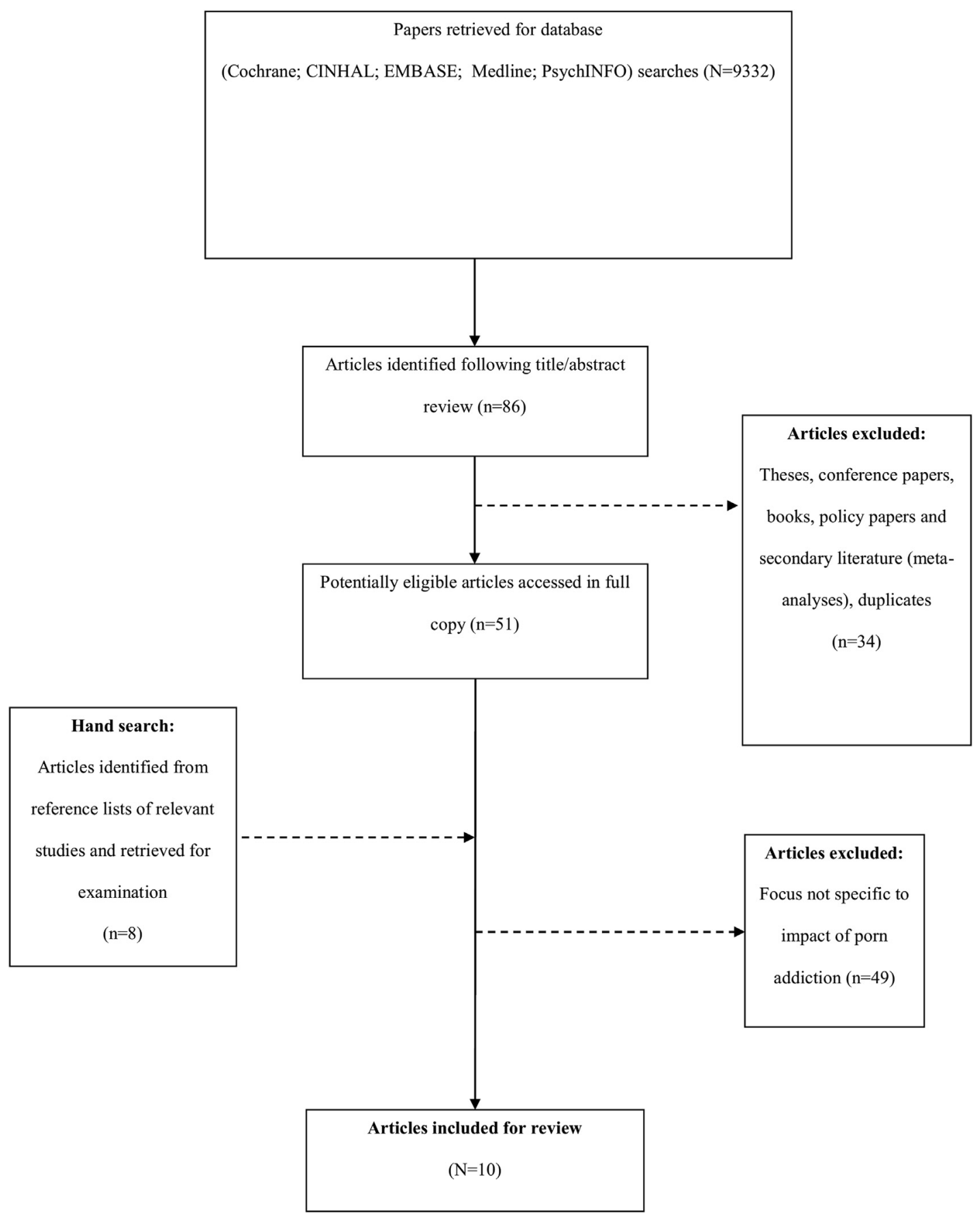

Figure 1. Quorum diagram illustrating the selection method. 
Table 1. General characteristics, definitions and impact of studies reporting the impact of SPPA $(n=8)$

\begin{tabular}{|c|c|c|c|c|}
\hline Study (year), location & Methodology & Sample characteristics & Measurements & Key findings (definition of SPPA and reported impact) \\
\hline \multirow{5}{*}{$\begin{array}{l}\text { Zitzman and Butler } \\
\text { (2009), USA }\end{array}$} & Qualitative: interviews & Gender: women ( $N=14)$ & SPPA: N/A & Definition \\
\hline & Analysis: NS & Age: 18-55 y (mean NS) & Impact: N/A & $\begin{array}{l}\text { "An impulse control disorder scalable to addictive proportions in } \\
\text { some individuals" ( } \mathrm{p} 212)\end{array}$ \\
\hline & & & & $\begin{array}{l}\text { (i) a neurophysiologic and psychological phenomena; (ii) producing } \\
\text { an intense, highly preoccupying altered state of conscious } \\
\text { awareness and experience; (iii) capacitating escape from reality } \\
\text { and/or escape into fantasy; (iv) which represents a maladaptive } \\
\text { coping strategy; ( } \mathrm{v} \text { ) due to pairing proximal, visceral reinforcers } \\
\text { with distal, more abstract punishments; ( vi) thereby setting up a } \\
\text { double approach-avoidance dynamic; (vii) with a definable cycle } \\
\text { of relapse; (viii) associated with failure or inability to avoid high- } \\
\text { risk behavior in the pursuit of the experience (eg, viewing } \\
\text { pornography at work); (ix) and producing personal, relationship, } \\
\text { and work impairment; }(\mathrm{x} \text { ) leading to repeated failed attempts to } \\
\text { quit; (xi) development of physical and/or psychological tolerance } \\
\text { or desensitization leading to diminishing returns; (xii) and } \\
\text { physical and/or psychological dependency or entrapment with an } \\
\text { associated existential experience of powerlessness }\end{array}$ \\
\hline & & $\begin{array}{l}\text { Population: conservative } \\
\text { Christian religious } \\
\text { affiliation }\end{array}$ & & Impact \\
\hline & & & & $\begin{array}{l}\text { Development of an attachment fault line in the relationship } \\
\text { stemming from perceived attachment infidelity, followed by a } \\
\text { widening attachment rift arising from wives' sense of distance } \\
\text { and disconnection from their husbands, culminating in } \\
\text { attachment estrangement from a sense of being emotionally and } \\
\text { psychologically unsafe in the relationship }\end{array}$ \\
\hline \multirow[t]{2}{*}{$\begin{array}{l}\text { Twohig et al (2009), } \\
\text { USA }\end{array}$} & $\begin{array}{l}\text { Quantitative: online } \\
\text { survey }\end{array}$ & Gender: men $(n=84)^{*}$ & SPPA & Definition \\
\hline & $\begin{array}{l}\text { Analysis: inferential } \\
\text { correlations }\end{array}$ & $\begin{array}{l}\text { Age: } 18-56 \text { y } \\
\quad(\text { mean }=22)\end{array}$ & $\begin{array}{l}\text { Self-report frequency } \\
\text { of use }\end{array}$ & “Problematic internet pornography viewing" \\
\hline
\end{tabular}




\begin{tabular}{|c|c|c|c|c|}
\hline Study (year), location & Methodology & Sample characteristics & Measurements & Key findings (definition of SPPA and reported impact) \\
\hline & & $\begin{array}{l}\text { Population: undergraduate } \\
\text { students }\end{array}$ & SCS & $\begin{array}{l}\text { “Currently, there is no agreement on how to describe/conceptualize } \\
\text { this behavior when it is problematic, but the similarities in the } \\
\text { 'borrowed' criteria offer clues to the nature of the problem. For } \\
\text { example, the characteristics of the disorders to which it is } \\
\text { compared (ie, obsessive compulsive disorder, impulse control, } \\
\text { substance use) would suggest that problematic viewing can be } \\
\text { triggered by a variety of events or experiences, most likely } \\
\text { involves intrusive and persistent thoughts, and is influenced by } \\
\text { powerful impulses or urges to view. It is also likely that it is } \\
\text { difficult to stop viewing as the viewing is appetitive and can } \\
\text { function to regulate unwanted emotion just as substance use or } \\
\text { compulsive behaviour can function to regulate unwanted } \\
\text { emotion." (p 224) }\end{array}$ \\
\hline & & & Impact: CBOSB & Impact \\
\hline & & & & $\begin{array}{l}\text { Measured cognitive problems (eg, worry) and experienced negative } \\
\text { consequences (eg, damaged important relationships) due to } \\
\text { sexual practices in past year if participants scored above the } \\
\text { median on the CBOSB subscales, they were considered to be } \\
\text { experiencing problematic outcomes as a result of their behavior }\end{array}$ \\
\hline \multirow[t]{10}{*}{$\begin{array}{l}\text { Cavaglion (2009), } \\
\text { Italy }\end{array}$} & $\begin{array}{l}\text { Qualitative: } 2,000 \\
\text { messages }\end{array}$ & Gender: men ( $\mathrm{N}=302)$ & SPPA: N/A & Definition \\
\hline & $\begin{array}{l}\text { Analysis: narrative } \\
\text { and interpretative }\end{array}$ & $\begin{array}{l}\text { Age: } 18-56 \text { y } \\
\quad(\text { mean }=20.6)\end{array}$ & Impact: N/A & $\begin{array}{l}\text { "Thus cyber-porn dependence, as reported by Italian participants in } \\
\text { the self-help group, may indicate a maladaptive behaviour which } \\
\text { interferes with functioning and is self-defeating, since its } \\
\text { outcomes, which are long-lasting and severe, impinge on the } \\
\text { continued well-being of the individual and that of the human } \\
\text { community of which the individual is a member." ( } p \text { 309) }\end{array}$ \\
\hline & & $\begin{array}{l}\text { Population: online } \\
\text { self-help groups for } \\
\text { "porn addicts" }\end{array}$ & & Impact \\
\hline & & & & $\begin{array}{l}\text { "Implications for personal well-being, social adaption, work, sex life } \\
\text { and family relations." (p 295) }\end{array}$ \\
\hline & & & & Progressive: lack of confidence in ability to manage own life \\
\hline & & & & Progressive: lack of concentration at work or school \\
\hline & & & & Progressive: isolation, dissociation \\
\hline & & & & Breakdown of self-esteem \\
\hline & & & & Sexual problems \\
\hline & & & & Shame \\
\hline $\begin{array}{l}\text { Cavaglion and Rashty } \\
\text { (2010), Italy }\end{array}$ & $\begin{array}{l}\text { Qualitative: 1,130 } \\
\text { messages }\end{array}$ & Gender: women ( $\mathrm{N}=\mathrm{NS}$ ) & SPPA: N/A & Definition \\
\hline
\end{tabular}




\begin{tabular}{|c|c|c|c|c|}
\hline Study (year), location & Methodology & Sample characteristics & Measurements & Key findings (definition of SPPA and reported impact) \\
\hline & $\begin{array}{l}\text { Analysis: narrative } \\
\text { and interpretative }\end{array}$ & Age: NS & Impact: N/A & Cyber-porn dependents' as defined by users \\
\hline & & $\begin{array}{l}\text { Population: online } \\
\text { self-help groups for } \\
\text { partners and friends } \\
\text { of "porn addicts" }\end{array}$ & & $\begin{array}{l}\text { "Porndependents, many of whom can be defined as addicted and } \\
\text { excessively busy and preoccupied with their online and offline } \\
\text { emotional and sexual activities." ( } p 277 \text { ) }\end{array}$ \\
\hline & & & & Impact \\
\hline & & & & $\begin{array}{l}\text { "Major patterns of distress primarily related to ambivalent } \\
\text { emotions and the formation of an ambiguous loss are discussed } \\
\text { as well as their implications on interpersonal, conjugal, and } \\
\text { sexual life." (p 270) }\end{array}$ \\
\hline & & & & $\begin{array}{l}\text { Eroded sense of integrity, inadequacy, mental (trauma), and } \\
\text { physical well-being }\end{array}$ \\
\hline & & & & Ambiguous loss-not being allowed to move on \\
\hline & & & & Rejection, guilt, shame and self-esteem \\
\hline \multirow[t]{8}{*}{ King (2003), USA } & $\begin{array}{l}\text { Qualitative: online } \\
\text { survey }\end{array}$ & Gender: women $(\mathrm{N}=40)$ & SPPA: N/A & Definition \\
\hline & Analysis: unknown & $\begin{array}{l}\text { Age: } 25-55 \text { y } \\
\text { (39\% 25-35; 34\% } \\
\text { 36-45; } 21 \% 46-55 ; \\
<5 \%>55 \text { ) }\end{array}$ & Impact: N/A & None \\
\hline & & $\begin{array}{l}\text { Population: wives of } \\
\text { pastors addicted to porn }\end{array}$ & & $\begin{array}{l}\text { Reference to sexual addiction and compulsion but only referred to } \\
\text { the use of porn }\end{array}$ \\
\hline & & & & Impact \\
\hline & & & & Loss (of relationships, debt, and identity) \\
\hline & & & & Isolation \\
\hline & & & & $\begin{array}{l}\text { Helplessness or hopelessness, confusion, guilt, shame or blame, } \\
\text { failure }\end{array}$ \\
\hline & & & & Devastating, trauma \\
\hline $\begin{array}{l}\text { Levin et al (2012), } \\
\text { USA }\end{array}$ & $\begin{array}{l}\text { Quantitative: online } \\
\text { survey }\end{array}$ & Gender: Males $(\mathrm{N}=143)$ & $\begin{array}{l}\text { SPPA: Self-report } \\
\text { frequency of use }\end{array}$ & Definition \\
\hline
\end{tabular}




\begin{tabular}{|c|c|c|c|c|}
\hline Study (year), location & Methodology & Sample characteristics & Measurements & Key findings (definition of SPPA and reported impact) \\
\hline & $\begin{array}{l}\text { Analysis: descriptive } \\
\text { statistics and O-order } \\
\text { correlations for each } \\
\text { variable, hierarchical } \\
\text { regression }\end{array}$ & Age: 20.68 y (mean) & Impact & $\begin{array}{l}\text { “One approach has been to conceptualize problematic viewing as a } \\
\text { form of addictive behaviour, in which individuals spend an } \\
\text { excessive amount of time engaging in compulsive viewing } \\
\text { despite negative consequences and attempts to abstain from } \\
\text { the activity (Cooper et al, 1999). A distinction can thus be made } \\
\text { between more common recreational users, where viewing has } \\
\text { minimal costs and can even have positive effects, and the } \\
\text { subsample of compulsive users, where viewing can be } \\
\text { particularly harmful (Cooper et al, 1999)." ( } p \text { 169) }\end{array}$ \\
\hline & & $\begin{array}{l}\text { Population: undergraduate } \\
\text { students }\end{array}$ & AAQ-II & Impact \\
\hline & & & DASS-21 & $\begin{array}{l}\text { "Viewing" and "avoidance" related to anxiety, problems (social, } \\
\text { family, romantic relationships, values, responsibilities, etc), and } \\
\text { poor social functioning }\end{array}$ \\
\hline & & & SFQ & \\
\hline & & & self-reported impact & \\
\hline \multirow[t]{5}{*}{$\begin{array}{l}\text { Pyle and Bridges } \\
\text { (2012), USA }\end{array}$} & $\begin{array}{l}\text { Quantitative: } \\
\text { experimental }\end{array}$ & Gender: women $(\mathrm{N}=186)$ & $\begin{array}{l}\text { SPPA: self-report } \\
\text { frequency of use }\end{array}$ & Definition \\
\hline & $\begin{array}{l}\text { Analysis: inferential } \\
\text { statistics }\end{array}$ & $\begin{array}{l}\text { Age: } \geq 18 \text { y } \\
\quad(\text { mean }=19.04)\end{array}$ & $\begin{array}{l}\text { Impact: self-reported } \\
\text { impact }\end{array}$ & $\begin{array}{l}\text { “... hypersexual disorder, a sexual desire disorder with an } \\
\text { impulsivity component and no accompanying paraphilic } \\
\text { behaviour ('sex addiction'), is being considered for inclusion in } \\
\text { the DSM-V (Kafka, 2010). One subset of this proposed disorder } \\
\text { specifies that the disordered behaviour is associated with } \\
\text { excessive pornography use ('pornography addiction')." (p 17I) }\end{array}$ \\
\hline & & Population: pastors' wives & & $\begin{array}{l}\text { "In terms of hypersexual disorder specifically, individuals often } \\
\text { engage in sexual behaviours for an excessive amount of time } \\
\text { while disregarding the risk for physical or emotional harm to self } \\
\text { or others (APA 2010)." (p. 17l) }\end{array}$ \\
\hline & & & & Impact \\
\hline & & & & $\begin{array}{l}\text { Perceived partner addictive porn use impacts perceived relationship } \\
\text { satisfaction = treatment need }\end{array}$ \\
\hline \multirow[t]{4}{*}{$\begin{array}{l}\text { Prause et al (2013), } \\
\text { USA }\end{array}$} & $\begin{array}{l}\text { Quantitative: } \\
\quad \text { experimental }\end{array}$ & $\begin{array}{l}\text { Gender: men and women } \\
\qquad(\mathrm{N}=50 ; \text { gender ratios } \\
\text { unclear })\end{array}$ & SPAA & Definition \\
\hline & $\begin{array}{l}\text { Analysis: inferential } \\
\text { statistics }\end{array}$ & Age: $>18$ y (mean unclear) & BIS/BAS & $\begin{array}{l}\text { VSS-P-those who report problems regulating their consumption } \\
\text { of visual sexual stimuli }\end{array}$ \\
\hline & & $\begin{array}{l}\text { Population: Undergraduate } \\
\text { Students }\end{array}$ & SES/SIS & $\begin{array}{l}\text { "Men and women who ... reported problems down-regulating their } \\
\text { use of VSS (VSS-P)." (p. 106) }\end{array}$ \\
\hline & & & SDI & Impact \\
\hline
\end{tabular}




\begin{tabular}{|c|c|c|c|c|}
\hline Study (year), location & Methodology & Sample characteristics & Measurements & Key findings (definition of SPPA and reported impact) \\
\hline & & & SCS & Found no impact on emotional regulation \\
\hline & & & Impact & \\
\hline & & & CBOSB & \\
\hline & & & PCES & \\
\hline & & & Emotion Ratings Scale & \\
\hline \multirow[t]{7}{*}{ Grubbs et al } & $\begin{array}{l}\text { Quantitative: online } \\
\text { survey }\end{array}$ & $\begin{array}{l}\text { Gender: study 1: men and } \\
\text { women }(\mathrm{N}=713 ; 338 \\
\text { women, } 370 \text { men, } 5 \\
\text { other/prefer not to say) }\end{array}$ & SPPA: CPUI-9 & Definition \\
\hline & $\begin{array}{l}\text { Analysis: descriptive } \\
\text { and inferential } \\
\text { statistics }\end{array}$ & $\begin{array}{l}\text { Gender: Study 2: time point } \\
\text { 1: men and women }(\mathrm{N}= \\
\text { 1,215; } 619 \text { women, } 422 \\
\text { men, } 6 \text { other/prefer not } \\
\text { to say), time point 2: men } \\
\text { and women }(\mathrm{N}=106 ; 39 \\
\text { women, } 67 \text { men) }\end{array}$ & Impact & $\begin{array}{l}\text { "Perceived addiction to Internet pornography refers to the } \\
\text { propensity of the individual to label the self as addicted to } \\
\text { pornography, regardless of the accuracy of such a self- } \\
\text { diagnosis." (p. 2) }\end{array}$ \\
\hline & & $\begin{array}{l}\text { Age: study 1: }>18 \text { y (mean } \\
\text { unclear); study } 2:>18 \text { y } \\
\text { (mean unclear) }\end{array}$ & CES-D & Impact \\
\hline & & $\begin{array}{l}\text { Population: Study 1: Adult } \\
\text { Internet users in the } \\
\text { United States registered } \\
\text { with Amazon's } \\
\text { Mechanical Turk (MTurk) } \\
\text { workforce database; } \\
\text { Study 2: Undergraduate } \\
\text { Students }\end{array}$ & GAD-7 & $\begin{array}{l}\text { “Perceived addiction to Internet pornography predicted } \\
\text { psychological distress above and beyond pornography use itself } \\
\text { and other relevant variables (eg, socially desirable responding, } \\
\text { neuroticism)" (p. 1). This relationship was found in a longitudinal } \\
\text { follow-up with a subset of the sample }(n=106)\end{array}$ \\
\hline & & & Perceived Stress Scale & \\
\hline & & & $\begin{array}{l}\text { State Anger Subscale } \\
\text { of State-Trait Anger } \\
\text { Scale }\end{array}$ & \\
\hline & & & $\begin{array}{l}\text { Neuroticism Subscale } \\
\text { of the Big Five } \\
\text { Inventory }\end{array}$ & \\
\hline $\begin{array}{c}\text { Bergner and Bridges } \\
(2002,) \text { USA }\end{array}$ & & Gender: women (N = NS) & SPPA: N/A & Definition \\
\hline
\end{tabular}




\begin{tabular}{|c|c|c|c|c|}
\hline Study (year), location & Methodology & Sample characteristics & Measurements & Key findings (definition of SPPA and reported impact) \\
\hline & & Age: NS & Impact: N/A & $\begin{array}{l}\text { In broad terms, this view is that the sexually compulsive person, } \\
\text { whether he or she is involved with pornography, paraphilic acts, } \\
\text { relentless cruising, or other activities, is in the business of } \\
\text { repairing his or her self-esteem. Sexual acting out, which in } \\
\text { many cases is more pronounced after a blow to the individual's } \\
\text { self-esteem, is on various accounts an attempt to restore one's } \\
\text { sense of personal worth after an insult to the masculine self- } \\
\text { image, to recover from explicitly sexual childhood degradations, } \\
\text { or to triumph over very damaging childhood sexual } \\
\text { indoctrinations. }\end{array}$ \\
\hline & & \multicolumn{2}{|c|}{$\begin{array}{l}\text { Population: online self-help } \\
\text { groups for partners of } \\
\text { "porn addicts" }\end{array}$} & Impact \\
\hline & & & & $\begin{array}{l}\text { New view of the relationship with negative effects relating to } \\
\text { themes of exclusivity, sexual desire, intimacy and inclusion, } \\
\text { investment in well-being of beloved, understanding, living a lie }\end{array}$ \\
\hline & & & & $\begin{array}{l}\text { New view of self with negative effects relating to themes of } \\
\text { sexually undesirable, worthless, and weak and stupid }\end{array}$ \\
\hline & & & & $\begin{array}{l}\text { New view of partner with negative effects relating to themes of liar, } \\
\text { unloving or selfish, inadequate father and husband, sick or bad?: } \\
\text { a critical dichotomy }\end{array}$ \\
\hline
\end{tabular}

EAQII = Acceptance and Action Questionnaire-II, BIS/BAS = Behavioral Inhibition Scale/Behavioral Activation Scale, CBOSB = Cognitive and Behavioral Outcomes Scale, CES-D = Center for

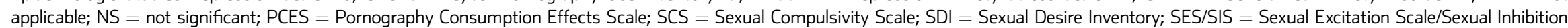
Scale; SFQ = Social Functioning Questionnaire; SPAA = self-perceived pornography addiction.

*Twohig et al excluded 140 women (mean age = 20.6 years) from all analyses due to "low rate of viewing by female participants." 
Table 2. Methodological characteristics of quantitative studies $(n=4)$ adapted from the Joanna Briggs Institute

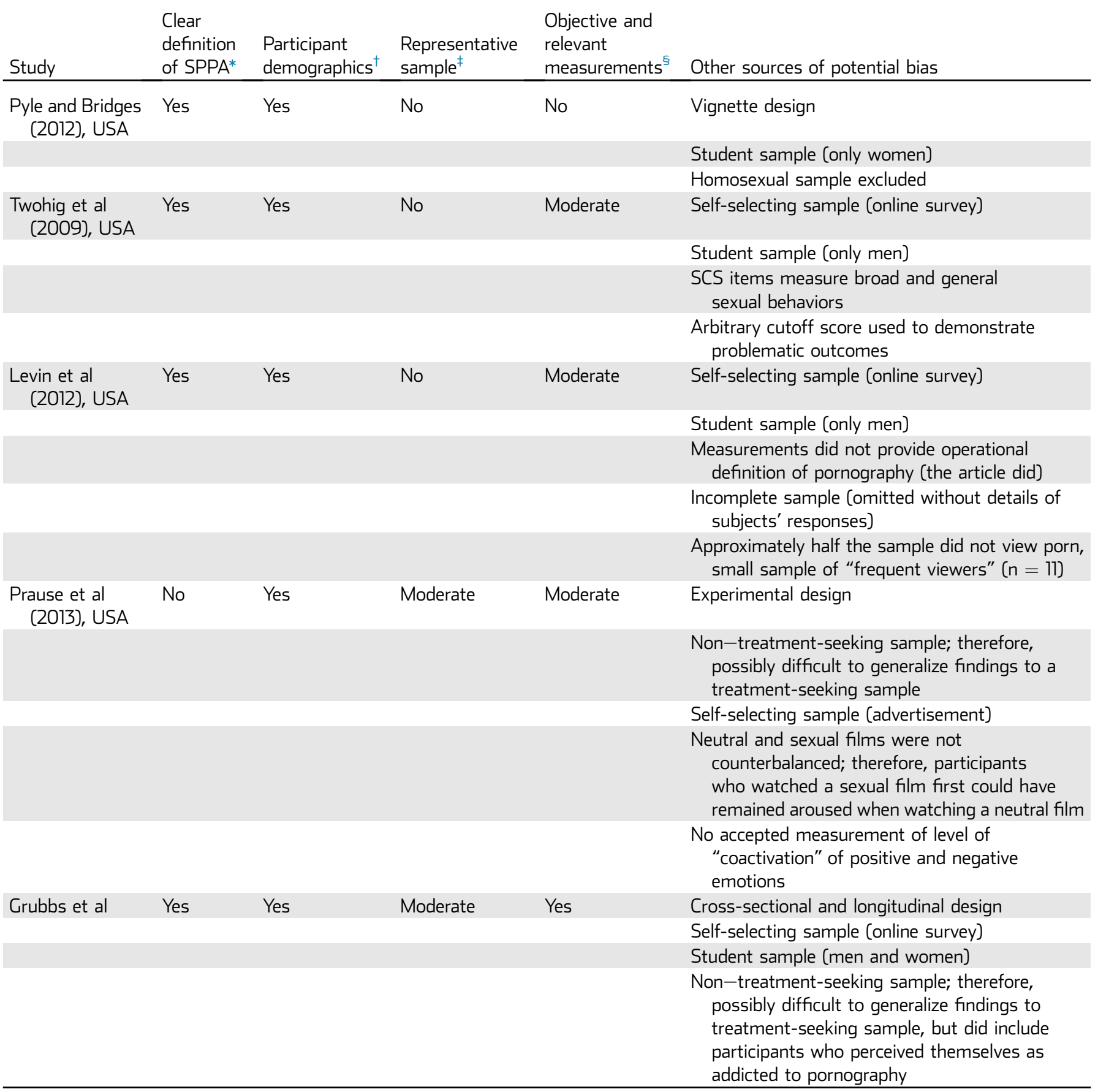

SCS = Sexual Compulsivity Scale; SPAA = self-perceived pornography addiction.

*Moderate $=$ a partial or incomplete definition of SPPA (or variant of) has been provided; no = no definition of SPPA (or variant of) has been provided; yes $=$ a clear definition of SPPA (or variant of) has been provided.

†Moderate = participant demographics information is limited; no = participant demographics are not reported sufficiently; yes = participant demographics are reported clearly.

$\ddagger$ Moderate = there is limited information regarding whether the sample represents individuals who perceive themselves as addicted to pornography; no $=$ there is not enough information to assess this sufficiently; yes = sample represents individuals who are self-perceived porn addicts.

§Moderate = study made some attempt to use relevant and objective measurements of SPPA and/or impact; no = study did not use relevant and objective measurements of SPPA and/or impact; yes = study used relevant and objective measurements of SPPA and/or impact. 
Table 3. Methodological characteristics of qualitative studies $(n=4)$ adapted from Tracy (2010)

\begin{tabular}{|c|c|c|c|c|c|c|c|c|}
\hline Study & $\begin{array}{l}\text { Clear definition } \\
\text { of porn addiction* }\end{array}$ & Rich rigor $^{\dagger}$ & Credibility $^{\ddagger}$ & Sincerity $^{\S}$ & Resonance & $\begin{array}{l}\text { Significant } \\
\text { contribution }^{q}\end{array}$ & $\begin{array}{l}\text { Ethical } \\
\text { clarity }^{\#}\end{array}$ & $\begin{array}{l}\text { Meaningful } \\
\text { coherence }^{* *}\end{array}$ \\
\hline $\begin{array}{l}\text { Zitzman and Butler } \\
\text { (2009), USA }\end{array}$ & Yes & Yes & Yes & Moderate & Moderate & Yes & Moderate & Yes \\
\hline $\begin{array}{l}\text { Cavaglion and Rashty } \\
\text { (2010), Italy }\end{array}$ & Moderate & Moderate & Moderate & No & Yes & Yes & Moderate & Yes \\
\hline Cavaglion (2009), Italy & Moderate & Moderate & Yes & Moderate & Yes & Yes & Moderate & Yes \\
\hline $\begin{array}{l}\text { Bergner and Bridges } \\
\text { (2002), USA }\end{array}$ & Yes & Moderate & Moderate & Moderate & Yes & Yes & Moderate & Yes \\
\hline King (2003) USA & No & Moderate & Moderate & Moderate & Moderate & Moderate & Moderate & Moderate \\
\hline
\end{tabular}

${ }^{*}$ Moderate $=$ partial or incomplete definition self-perceived pornography addiction (or variant of) has been provided; no = no definition of self-perceived pornography addiction (or variant of) has been provided; yes = clear definition of self-perceived pornography addiction (or variant of) has been provided.

†Moderate = study offers limited information regarding its method and analyses; no = study does not provide enough information to assess this sufficiently; yes = study offers appropriate and sufficient descriptions and explanations for its method and analyses.

¥Moderate = research might be trustworthy and credible but there are limited descriptions of the methodology and findings; no = study does not provide enough information to assess this sufficiently; yes = research appears trustworthy and plausible in light of authors' descriptions.

§Moderate = authors offered limited self-reflexivity and transparency regarding their biases and challenges; no = authors do not provide enough information to assess this sufficiently; yes = authors were self-reflexive and transparent regarding their biases and challenges.

$\|$ Moderate $=$ research provides limited insight and impact to the reader; no = study does not provide enough information to assess this sufficiently; yes $=$ research provides insight and findings that affect the reader.

TModerate = extension of knowledge in this area is limited; no = study does not extend knowledge in this area; yes = research extends knowledge in this research area.

\#Moderate $=$ there is limited consideration of the ethical implications of the authors' practices and findings; no = authors did not provide enough information to assess this sufficiently; yes = authors considered the ethical implications of their practices and findings.

**Moderate = research attempted to interconnect methods with stated goals; no = study did not provide enough information to assess this sufficiently; yes $=$ research used methods coherently to achieve its stated goals. 